\title{
Assessing relative spending needs of devolved government: the Case of Healthcare Spending in the UK
}

\author{
Rob Ball ${ }^{\mathrm{a}}$, David King ${ }^{\mathrm{b}}$, and David Eiser ${ }^{\mathrm{c}}$ \\ September 2012
}

University of Stirling

\author{
${ }^{a}$ Professor of Public Management \\ ${ }^{\mathrm{b}}$ Professor of Economics \\ ${ }^{\mathrm{c}}$ ESRC Research Fellow
}

\begin{abstract}
The UK's devolved administrations (DAs) rely on block grants to finance most of their spending, but the level of grants allocated to them is not determined by any estimate of their spending needs. There are increasing calls to replace the current grant allocation mechanism with one which explicitly considers the DAs' spending needs, although some commentators argue that assessing their needs is not practicable, given the normative dimension in defining need. This paper compares two existing formulae for estimating healthcare spending needs (used by the NHS to allocate resources within England and Scotland) by applying both formulae to the DAs. It is found that these formulae provide very similar estimates of the DAs' healthcare spending needs, and both formulae imply that the current distribution of resources across the DAs may be inequitable. The implications for the possible development of grant allocation mechanisms based on estimates of spending needs are discussed.
\end{abstract}

This research has been funded through ESRC Research Grant RES-062-23-2814, 'Development of needs-based funding models for the devolved territories in the UK'. The grant runs from March 2011 - February 2013. 


\section{Introduction}

Globally there is a trend towards decentralisation of public sector activity (LAGO-PEÑAS et al. 2011). As the significance of devolved, or sub-central, tiers of government in public service delivery increases, the question of how to fund devolved levels of government becomes more important. A study of 23 OECD countries found that on average around a quarter of central government tax revenue was spent on inter-governmental grants (BLÖCHLIGER and KING, 2006).

Among OECD countries, a variety of allocation mechanisms have been established for allocating grant to sub-central government, often involving some assessment of the spending needs of those governments. At one end of the spectrum, Australia has one of the most sophisticated spending needs assessments (KAY et al, 2005; SELECT COMMITTEE ON THE BARNETT FORMULA, 2009), with States' expenditure needs estimated separately across 14 expenditure areas (COMMONWEALTH GRANTS COMMISSION, 2010). At the other end of the spectrum, Spain uses a comparatively simple formula to inform the allocation of resources to Autonomous Communities (BÖSCH, 2009).

For over 30 years, the devolved administrations (DAs) in the UK's three devolved territories (Scotland, Wales and Northern Ireland) have relied on a block grant from the UK government to finance the majority of their spending. This block grant continues as the main source of funding for the DAs even following the substantial devolution of policy and spending autonomy that began in 1997.

Recent years have seen increasing debate around how the DAs should be funded, and in particular the extent to which they should have greater tax raising powers. The Scotland Act (2012) will allow the Scottish Parliament to vary income tax rates and retain a proportion of all income tax raised in Scotland, and devolution of further fiscal autonomy seems likely in the longer term. The Commission on Devolution in Wales is exploring the case for devolution of similar tax-raising powers to the Welsh Assembly, whilst a Ministerial Working Group is exploring the possibility of devolving Corporation Tax to Northern Ireland (NI).

Yet with the debate around fiscal autonomy it is easy to forget that some element of block grant will remain an important- perhaps the most important - part of the DAs funding package for the foreseeable future (this is true for Wales and NI even if Scotland were to vote for independence in 2014). There has for a long time however been substantial dissatisfaction with the way in which the DAs block grant is determined. This dissatisfaction largely centres on the fact that the determination of the block grant is not based on any estimate of the DAs' spending needs. Instead, changes in grant 
from one year to the next are calculated as a function of the change in spending in England, and the population share of each DA.

The question of how the block grant to the UK's DAs should be determined has recently been reignited by two high profile reports. The House of Lords Select Committee on the Barnett Formula (SELECT COMMITTEE ON THE BARNETT FORMULA 2009) and the Holtham Report (INDEPENDENT COMMISSION ON FUNDING AND FINANCE IN WALES, 2010) recommended that the current approach to determining the block grant should be replaced by some form of expenditure needs assessment, which would explicitly allocate grant to the DAs based on estimates of their relative spending needs. Other authors however have highlighted the difficulties in estimating spending needs, given that the question of what constitutes a need is inherently normative (MORGAN, 2002).

However, it is also true that spending needs assessments are used regularly to estimate the spending needs of local authorities, schools and health trusts in the UK (SMITH, 2007), with grant allocations often being determined on the basis of these estimates. This raises a question about how some of these existing methods of spending needs assessment might estimate the spending needs of the UK's devolved territories: would different formulae produce widely different estimates of the UK territories' spending needs (thereby justifying the views of the needs assessments sceptics), or would different formulae produce similar estimates of the UK's territories spending needs?

This paper compares two formulae for assessing the healthcare spending needs of territories. One formula is used by the National Health Service (NHS) in England to allocate resources to Primary Care Trusts (PCTs); the other formula is used by the NHS in Scotland to allocate resources to Health Boards in Scotland (throughout the remainder of this paper, the term PCT is used to refer to Primary Care Trusts in England, Health Boards in Scotland and Wales, and Health and Social Care Trusts in $\mathrm{NI})$. The paper compares the two formulae by applying each in turn to the UK territories. The two formulae have been developed separately over several decades, overseen by different governments with varying political priorities. Thus it might be expected that the two formulae would provide quite different estimates of the spending needs of the UK territories, in which case there would seem to be limited scope for using them as part of a UK-wide system of estimating spending need. On the other hand, if the two formulae provide similar estimates of the UK DAs' relative spending needs, the scope for developing an approach to estimating the spending needs of the DAs looks more possible.

The analysis focuses on health services for two reasons. First, the National Health Services in both England and Scotland have developed sophisticated mechanisms for measuring the healthcare 
spending needs of territorially based health trusts, and these formulae form the basis of our analysis. Second, healthcare is an important element of devolved policy, accounting for around one third of the budget of each DA. Healthcare is of course just one element of DA spending, and thus it could be argued that developing an estimate of the DA's healthcare spending needs alone would not necessarily help in developing an alternative to the Barnett Formula (given that the Barnett Formula is used to determine all elements of the DA's block grant). The objective of this paper however is to consider in the first instance whether there are similarities in the English and Scottish approaches to estimating healthcare spending needs, and following this to consider what the implications are for the development of alternative funding mechanisms for the UK's DA's in the future.

The remainder of the paper is structured as follows. Section 2 describes the political economy of the current funding arrangements for the UK DAs, and sets out issues relating to the territorial differences in healthcare spending. Section 3 provides an overview of the healthcare needs assessment formulae that are used to allocate healthcare resources within England and Scotland, while Section 4 describes in more detail how these formulae were applied to the UK territories. Section 5 presents the results, focusing on how the two formulae assess the health spending needs of the UK territories. Section 6 concludes.

To preview our results, we find that the existing English and Scottish NHS healthcare allocation formulae do both provide similar estimates of the devolved territories healthcare spending needs, despite having been developed from different data in different socio-political contexts. The results also imply that there is some inequity in the current allocation of resources across the UK. We argue that these findings justify the current interest in replacing the Barnett Formula with a formula for estimating spending needs, but that there remain a number of political challenges to overcome if this is to be achieved.

\section{The political economy of funding the devolved territories}

The spending of the DAs is largely financed through a block grant from the UK government (the DAs have some ability to raise funding indirectly through council tax and business rates, although this position is evolving). This block grant is determined as a function of two things: the baseline and an increment. The baseline is simply the grant in the previous period, whilst the increment is determined by the Barnett Formula. The Barnett Formula determines the change to the DAs' budget based on changes in spending on comparable (i.e. devolved) services in England, and the population share of each DA (HM TREASURY, 2010a). For example, if the UK government announces a $f 100 \mathrm{~m}$ 
increase in health spending, $99 \%$ of all health spending is devolved, and Scotland's population is $10 \%$ of England's, then the Scottish Government would see an increase in its budget of $£ 9.9$ million.

The Barnett formula has been criticised because it makes no attempt to estimate the spending needs (other than population shares) of the devolved territories (MCLEAN et al, 2008). This has led to the formula being claimed variously to be overly generous to some territories (in particular Scotland but also NI) and less generous to others (Wales), (MORGAN, 2001; MCLEAN and MCMILLAN, 2003; MACKAY, 2005).

Given this criticism, a case has been made to replace the Barnett formula with some form of expenditure needs assessment (INDEPENDENT COMMISSION ON FUNDING AND FINANCE FOR WALES, 2010), and specifically one which ensures 'those parts of the UK which have a greater need receive more public funds to help them pay for the additional levels of public services they require as a result' (SELECT COMMITTEE ON THE BARNETT FORMULA, 2009, Paragraph 81).

Criticism of the Barnett formula's insensitivity to spending needs is not new. A legitimate question to ask is why Barnett has remained the preferred mechanism for allocating grant to the UK territories, especially given the apparent disadvantage to citizens of England and Wales made by the current pattern of Barnett-based allocations.

The continued reliance on Barnett is usually explained in relation to issues of political economy. On the one hand, some commentators have characterised the Barnett formula as part of a more nuanced 'formula plus influence' system of funding which has advantages for both the central and devolved governments (CHRISTIE and SWALES, 2010). According to these authors, the grant allocations to the devolved territories reflect 'the greater cultural and geographic distance of these regions from the centre and the greater political coherence and the more powerful bargaining power that the peripheral [i.e. devolved] regions held' (CHRISTIE and SWALES, 2010). Modelling this as a sequential game, HALLWOOD and MACDONALD (2009) make a similar point about the role of devolved territories' threat to secede from the Union in maintaining a territories grant at a level above that which the territory might receive should grant be based on 'need' alone, an argument that was similarly made by MCLEAN and MCMILLAN (2003) in commenting on the formula's apparent generosity to Scotland and NI relative to Wales.

Other commentators highlight the normative dimension of spending needs assessment, and the potential difficulties in politicians reaching consensus on what a needs-based funding formula for the UK territories would look like in respect of which indicators might be used, and how they might be weighted (MIDWINTER, 2002). 
Thus although there is widespread recognition of the major limitation of Barnett in relation to its insensitivity to spending need, the formula's longevity seems due to its more nuanced advantages as the codification of a bargaining outcome (SMITH, 2003), as well as the difficulties of agreeing how a needs formula might be developed. In relation to the latter issue, both the House of Lords and Holtham Commission reports made suggestions for the type of indicators that might be included in a simple but transparent needs assessment formula, arguing that the implementation of such a formula could be overseen by an independent commission, similar to the operation of the funding of Australian states. In relation to the former issue, there is an argument that interest in replacing Barnett may become stronger following devolution of some level of tax autonomy to Scotland and the other devolved nations, combined with increasing divergence in political priorities across the UK territories following devolution (JEFFERY 2012); and the emergence of a stronger English political identity that questions the capacity of the current UK-level political institutions to pursue and defend English interests (LODGE et al. 2012).

Turning to healthcare specifically, per capita spending on health services varies substantially across the UK territories (Table 1). As an index relative to English per capita spending on health services, per capita spending on health services in Scotland is almost $14 \%$ higher, while it is $8 \%$ higher in Wales and 9\% higher in NI.

The differences in per capita spend on health services are largely a function of differences in Barnett formula-derived grant allocations to the DAs. Indeed, spending on health makes up a similar proportion of total DA spending in each territory, accounting for around one third of devolved spending (Table 1).

As discussed in the preceding section, these Barnett-Formula derived grant allocations have nothing to do with any estimate of spending needs for health (or any other service). Thus although there is some evidence that the UK's devolved territories (and Scotland in particular) may have higher health spending needs than England on some measures (HANLON et al., 1999; McLAREN et al., 2010; NAO, 2012), the spending patterns across the UK territories do not reflect any type of estimate of healthcare spending need. If the Barnett allocations do coincide with any estimate of health spending need, this would be by accident, rather than design.

If they so chose, the DAs could increase spending on healthcare, but this would necessarily come at the expense of reductions in spending elsewhere within the DAs portfolio of devolved services. Given the significance of healthcare spending in DA budgets, the scope for varying healthcare spend without negatively impacting on other areas of the budget is extremely limited. 


\section{Needs-based funding models in the NHS}

The way in which grant is allocated to the UK's devolved territories, which makes no attempt to estimate those territories spending need, contrasts markedly from the way in which resources are allocated within the territories to Primary Care Trusts, where sophisticated needs estimates models are used to estimate spending needs. The NHS in England has used an expenditure needs assessment formula to calculate revenue allocations to PCTs since 1980. The NHS in Scotland has used its own needs assessment formula for determining revenue allocations to Health Boards since 1979. NI also uses a formula funding approach to allocate resources to Health and Social Care Trusts, although the detail of this formula is not considered in this paper. Wales is the only UK territory which does not at present use a formula approach for determining resources to its Health Boards; its allocations are made on the basis of ministerial negotiation.

The English and Scottish formulae use a weighted capitation approach to determine the level of resources allocated to PCTs (DEPARTMENT OF HEALTH, 2009a; NHS SCOTLAND RESOURCE ALLOCATION COMMITTEE, 2007). The principle of the weighted capitation approach is to calculate shares of the overall budget that should be allocated to each PCT, in order that each PCT can provide similar services, given the characteristics of the population in its area. This is done by adjusting the population in each PCT to take account of both the health needs of its population and any additional costs associated with delivering services in that area. In both the English and Scottish capitation formulae, the needs indicators and weights used have been identified by modelling healthcare utilisation at the small area level as a function of population characteristics and the availability of healthcare facilities.

The English and Scottish allocation formulae each consist of a number of blocks, or elements, representing different aspects of healthcare delivery (for example, Acute Care, Maternity Care, Care of the Elderly, Mental Health Care, and so on). For each of these blocks, both the English and Scottish capitation formulae adjust each PCT's population to take account of three broad factors that are seen to influence spending need:

- The age structure of the population, recognising that need for healthcare varies according to age, and in particular, the young and elderly, whose populations are not evenly distributed across the country.

- Additional needs, i.e. the fact that populations of the same age distribution display different levels of need for healthcare. Higher levels of underlying morbidity (illness) and socioeconomic deprivation are likely to increase demand for healthcare. 
- Cost, i.e. the fact that the cost of providing healthcare may be higher in remote rural areas because of diseconomies of scale, or in large urban areas where market forces result in higher factor costs.

To illustrate, consider the derivation of the index for Acute Care in the Scottish formula (Acute accounts for $52 \%$ of resources allocated through the Scottish formula in total). PCTs are allocated a sum for every individual within each of 20 age categories. For example, a PCT is allocated $f 989$ for each male aged 0-1, and £1,749 for each male aged 75-79. Each PCT's additional need for resources related to morbidity and life circumstances is then calculated based on standardised rates of mortality and long-term limiting illness in the area. Finally, the excess costs are derived based on the proportion of the PCT population living in one of ten categories of rurality.

The English formula's approach to assessing spending needs for Acute Care (which accounts for $51 \%$ of resources allocated through the formula) is as follows. Age and additional needs are assessed simultaneously using a 'one-stage' approach. This allows the relationship between age and additional need to vary across 18 different age bands, with 12 separate needs indicators entering the equation. Unavoidable excess costs are calculated by considering differences in wage, land and building costs relative to the national average.

The capitation formulae are used to inform the allocation of significant resources. In the 2009/10 financial year, the weighted capitation formula informed the allocation of some $f 80$ billion to NHS Trusts in England (DEPARTMENT OF HEALTH, 2009b), representing over $80 \%$ of health revenue expenditure in the country (HM TREASURY, 2010b). Scotland's capitation formula informs the allocation of some $£ 7$ billion, around $85 \%$ of all funding to Health Boards and $67 \%$ of all NHS Scotland expenditure (NHS SCOTLAND RESOURCE ALLOCATION COMMITTEE, 2007). Both the Scottish and English formulae are updated on a regular basis, overseen by independent committees in each country.

The healthcare allocation formulae have been criticised on a variety of grounds, including the statistical methods used, the appropriateness of the 'utilisation method', and data selection (STONE and GALBRAITH, 2006; GALBRAITH and STONE, 2011), leading to assertions that the formulae produce results which are arbitrary and unfair. Nonetheless, utilisation-based capitation formulae remain the preferred mechanism of the NHS in England, Scotland and NI to allocate healthcare resources. Indeed, the Health White Paper for the NHS in England appears to further support the case for determining healthcare resources by formula (DEPARTMENT OF HEALTH, 2010). It envisages an NHS Commissioning Board that will set GP-Practice level budgets. This allocation seems likely to 
be based on person-based resource allocation methods, which use (anonymised) individual level data to predict healthcare utilisation for a given GP-practice registered population (NUFFIELD TRUST, 2009). A recent report (NAO, 2011) concluded that the health allocation formula used in England is transparent, and that the broad approach [to allocating health resources by formula] is appropriate. Thus formula-based allocation of healthcare resources look likely to remain in place for the foreseeable future.

\section{Approach and data}

This section describes in further detail the structure of the English and Scottish healthcare allocation formulae, and how the two formulae were applied to the territories of the UK. It is worth re-iterating that these formulae have not been developed by the authors; the formulae have been developed over many years by the respective health services in the two countries, and the aim of this paper is to apply each formulae to all health trusts in the UK.

Although the general structure of the English and Scottish formulae is the same, there are some differences between the formulae at a more detailed level. Firstly, there are some differences between the formulae in terms of the components of health covered. The English formula is used to allocate resources to three broad components of healthcare: Hospital and Community Health Services (HCHS); Prescribing (the drugs bill); and Primary Medical Services (PMS, i.e. GP surgeries and out-of-hours services). The weights attached to each of these three elements are $76 \%, 12 \%$ and $11 \%$ respectively. The Scottish formula also allocates resources for HCHS (weighted 85\%) and Prescribing (weighted 15\%), but not PMS (in Scotland, resources for PMS are allocated outwith the formula).

Secondly, there are differences between the two formulae in terms of the specific indicators used and the weights attached (Table 2 shows the indicators used). Further detail on how these indicators are weighted and combined to estimate the relative spending needs of each PCT are set out in guidance documents (NHS SCOTLAND RESOURCE ALLOCATION COMMITTEE, 2007 for detail of the Scottish formula; and DEPARTMENT OF HEALTH, 2009a for details of the English formula). The precise structure of the two formulae is too complex to outline here, but readers who wish to understand the mechanics of the formulae in more detail can consult the respective guidance documents referred to above, or BALL et al., (2012) which sets out details of how the Scottish formula was applied, and BALL et al., (2011) which sets out details of how the English formula was applied.

An interesting difference between the two formulae is in relation to cost. In assessing the costs associated with delivering healthcare in different geographical areas, the English formula relies 
largely on indicators of factor costs, specifically wages, land values and premises costs. The Scottish formula in contrast focuses more on the effects of sparsity on healthcare delivery costs. The implications of this difference for the pattern of resources made by the two formulae is discussed in the results section.

A further difference between the formulae is that the English formula includes an adjustment for health inequalities $(\mathrm{HI})$, whereas the Scottish formula does not. Before the introduction of $\mathrm{HI}$ to the English formula, the objective of the English formula was to allocate resources so as to enable PCTs to commission similar levels of healthcare for populations with similar healthcare needs. The HI element introduces an additional objective to the formula, specifically to allocate resources so as to 'contribute to the reduction of avoidable inequalities in health'. The effect of the health inequalities element on the allocation of resources can be significant as it implies that resources should be distributed not only to reflect the existing burden of sickness but also targeted to reduce the health gap between the most and least advantaged groups. In Scotland, health inequalities are addressed outwith the formula, via specific grants. The implication of these different approaches to addressing health inequalities are discussed in the results section.

In order to apply the English and Scottish healthcare capitation formulae across all UK territories, the data described in Table 2 was collated for each PCT in England, Wales, Scotland and NI. This resulted in data being collated for some 174 PCTs in total'. The data was applied to the two formulae to determine a relative expenditure needs score for each PCT, and by aggregation, each DA.

\section{Results}

The English and Scottish NHS resource allocation formulae's estimates of the healthcare spending needs of the devolved territories are shown in Table 3. The results are expressed as an index relative to English per capita healthcare expenditure need of 1 . Thus an index of 1.1 for a territory implies spending need of $10 \%$ above England's, whilst a score of 0.9 for a territory implies spending need $10 \%$ below England's. The results in Table 3 combine the results from the different components of the formulae (i.e. HCHS, Prescribing and PMS) into a unified estimate of healthcare spending needs.

The results for the English formula exclude the Health Inequalities element. This is so that the two formulae are compared on a like-for-like basis, i.e. where the objective of both formulae is to allocate resources to ensure 'equal access to healthcare for those in equal need'. The implications of including the Health Inequalities element of the English formula (which as noted above introduces a second objective of reducing avoidable health inequalities) are discussed subsequently. 
The first point to note is that the two formulae provide relatively similar estimates of healthcare spending need (bottom row). Wales' per capita healthcare expenditure need is estimated almost identically by the two formulae (9.5\% above England according to the English formula and $9.7 \%$ above England according to the Scottish formula). NI's per capita need ranges from $2.4 \%$ to $3.9 \%$ higher than England's on the English and Scottish formulae respectively. For Scotland there is somewhat more variation between the two formula, with needs ranging from $7-11 \%$ above England's according to the two formulae.

Reasons for the divergence between the formulae results can be discerned by considering how the formulae assess the devolved territories for the three core elements of the formulae: age, additional needs, and costs.

Healthcare expenditure needs increase with age and therefore Wales, which has a slightly older population, is allocated more resources per capita under both the Scottish and English formulae (the English formula allocates Wales an additional $4.5 \%$ resources per capita on account of the age distribution of its population, whilst the Scottish formula allocates Wales an additional 3.5\% per capita; the differences between the two formulae being due to slightly different weights attached to different age groups in the formulae' estimates of need). Conversely NI which has a younger population is allocated fewer resources per capita than England by both formulae. Scotland has a similar age distribution as England and thus is allocated very similar resources (around 1\% more than England by the English formula and $0.3 \%$ less than England by the Scottish formula).

The additional needs index covers a PCT's need for healthcare as a result of underlying morbidity or social deprivation. The second line in Table 3 reveals that all three devolved territories have significantly higher 'additional' needs than England according to both formulae. However, the English formula appears more generous to Wales and NI than the Scottish formula, but the Scottish formula is more generous to Scotland than the English formula is.

The difference between the two formulae in how they score the territories relates to the indicators that the formulae use. In the Scottish formula, two indicators predominate - the standardised under- 75 mortality rate and the standardised long-term limiting illness rate explain around three quarters of the variation in HCHS additional need scores. The English formula also places significant weight on death rates by age band, but considers a wider range of socio-economic measures of deprivation (see Table 2).

The English formula thus includes several indicators of labour-market and wider socio-economic deprivation that tend to favour the most deprived inner-city areas. This hypothesis is confirmed by 
further analysis, not reported here but available from the authors, which compares the 'additional need' scores of all UK PCTs individually according to the two formulae. This analysis shows that, relative to the English formula, the Scottish formula allocates relatively fewer resources for 'additional needs' to London PCTs in particular, but also to other deprived urban areas such as Manchester and Knowsley. In contrast, the Scottish formula allocates relatively more resources to less urban areas.

The cost index for the devolved territories, shown in the third line of Table 3, shows minor differences between the formulae in how they assess the excess costs associated with delivering healthcare. According to the English formula, the DAs face lower per capita healthcare delivery costs than England. The Scottish formula on the other hand indicates that the DAs face marginally greater per capita delivery costs than England. The reason for this difference is that the English and Scottish costs assessments emphasise different factors. The English formula takes into account labour and facilities costs in different parts of the country. This tends to allocate more resources to London and the southeast where such costs are higher. The effect of the Scottish cost index in contrast is largely to compensate rurally based PCTs for the higher costs of delivery in remote and sparsely populated areas.

So in terms of cost, both the English and Scottish formulae do tend to shift resources between PCTs; but at national level these adjustments tend to make relatively little difference. This is because a relatively small proportion of the population of each country are effected by such adjustments (this is particularly true of the Scottish cost element, which allocates significant additional per capita resources to very remote areas, but these adjustments can be accommodated by very minor reductions in per capita allocations to other parts of the country given how few people live in very remote areas).

The fact that the Scottish formula adjusts more resources to rural areas but the English formula adjusts more resources to urban areas is neither surprising nor alarming. Both formulae are based on evidence as to how the costs of healthcare delivery vary across different areas - the Scottish formula does not allocate many additional resources to high-cost urban areas because it has few of these areas in its territory; likewise the English formula does not adjust resources particularly to remote island PCTs because there are no such PCTs in England on which evidence for the costs associated with such areas could be assessed (the English formula makes no special allowance for the Isles of Scilly, doubtless because the Isles of Scilly represent just a small proportion of the population residing in the Cornwall PCT). Thus the differences between the two formulae seem unlikely to be due to fundamental normative differences about whether for example, the costs 
associated with higher labour costs in urban areas should be compensated for, and more to do with the sample of geographical areas on which the cost formulae have been derived.

The two formulae can be compared further by considering how they would each allocate resources across the regions of England as well as the territories of the UK. Figure 1 compares the per capita healthcare allocations made by the English formula ( $x$-axis) with the per capita healthcare allocations made by the Scottish formula (y-axis). The dotted $45^{\circ}$ line represents equality between the two formulae - if a region is located above this line its needs are estimated to be higher by the Scottish formula; if a region is located below the line its needs are estimated to be higher by the English formula.

For most regions, the two formulae provide very similar estimates of spending needs. For the South East, East, East Midlands, Yorkshire and the Humber, West Midlands, Northern Ireland, the North West and Wales, the two formulae estimate needs within 3 percentage points. For Scotland and the North East of England, the Scottish formula allocates more resources than does the English formula, and this is mainly due to the fact that both these areas have relatively high rates of mortality and self-assessed morbidity, indicators which are weighted fairly heavily by the Scottish formula in estimating 'additional needs' for healthcare (the Scottish formula also does not penalise these areas so much for the fact that they have relatively lower labour and other factor costs). The healthcare spending needs of the South West region are estimated to be about five percentage points higher by the Scottish formula compared to the English formula. This results from a combination of factors, including: that the region has a relatively elderly population which the Scottish formula appears to compensate slightly more than the English; that the South West is allocated fewer 'additional needs' resources by the English formula because it performs relatively well on measures of socio-economic disadvantage; and that the region benefits to a small extent by the Scottish formula's allocation of resources to rural areas on account of the additional costs incurred in delivering healthcare in those places.

The main outlier is London. The Scottish formula estimates London's per capita needs to be $9 \%$ lower per capita than the English average, whereas the English formula estimates London's per capita needs to be $1 \%$ higher than the English average. There are two main drivers of this difference, both alluded to already. First, the English formula estimates that London has higher 'additional needs' than the Scottish formula does, because the English formula relies more heavily on indicators of labour market disadvantage and ethnic minority population, whereas the Scottish formula relies more heavily on mortality and indicators of self-assessed morbidity as proxies for 'additional need'. Second, the cost element of the English formula allocates resources to areas which experience high 
labour and other factor costs, whereas the extent to which the Scottish formula compensates for these types of costs is more limited. If the English formula results are calculated excluding the cost element, then the two formulae's estimate of the relative spending needs of the UK regions are closer (Figure 2).

The results so far discussed assume that the objective of both formulae is to enable PCTs to commission similar levels of healthcare for populations with similar healthcare needs. As noted previously however, the English formula also contains an objective to reduce avoidable health inequalities. The health inequalities element of the English formula allocates resources towards areas that have lower Disability Free Life Expectancy (DFLE), an indicator which combines information on mortality and morbidity. The weight attached to the DFLE indicator is determined by Ministers (unlike the other elements of the formula, the weight cannot be determined through analysis of existing healthcare utilisation). It was weighted 15\% in 2009/10 and 2010/11 before being reduced to $10 \%$ in 2011/12. Within England, the distributional effects of the health inequalities element are significant across PCTs, with the effect of the health inequalities element being to direct funding from southern and eastern England to the north of England and inner London (NATIONAL AUDIT OFFICE, 2011).

Inclusion of the health inequalities element would also have significant distributional consequences at a UK level, and specifically to additional resources being allocated to the devolved territories, relative to England. After incorporating the $\mathrm{HI}$ element at $15 \%$ into the English formula, the estimated relative per capita spending needs of Wales, Scotland and $\mathrm{NI}$ increase to $16 \%, 12 \%$ and $9 \%$ higher than England's, respectively (Table 4). Inclusion of the $\mathrm{HI}$ indicator in the Scottish formula (which is shown in Table 4 for comparison purposes only - the Scottish formula does not in practice adjust for Health Inequalities) results in similar magnitude increases in the overall scores for each devolved territory.

There has been criticism of what is seen by some to be an arbitrary weight attached to the indicator, and debate around how the indicator should be weighted (HEALTH OF COMMONS HEALTH COMMITTEE, 2009). This is an illustration of normative dimension to formula funding; that there is no 'ineluctable scientific logic' to the choice of one formula over another, and policy judgements that have important issues for resource allocation are required at all stages of formula funding (MIDWINTER, 2001; MCLEAN AND MACMILLAN, 2003; SMITH, 2003). This leads to much lobbying (on the part of grantees) for a particular outcome, while the government has the ability to tweak the pattern of allocations to favour their electoral ambitions. There are ample examples of such manipulation in relation to the funding formulae for local government. JOHN and WARD (2001) for 
example showed that local government resources were targeted at swing districts and conservativeflagship districts during the Conservatives time in office, while HILBER et al., (2011) demonstrate that resources were targeted at Labour swing districts during Labour's 13-year period in office.

Allocations to PCTs may be less politically motivated (given that there are no elections of members to PCTs), but possibly only marginally so - CARR-HILL et al (1997) describe how Conservative and Labour governments manipulated the healthcare formula to distribute relatively less (then more, respectively) resources to health trusts in inner cities.

Despite these issues that are inherent to formula funding, they do not detract from the issue that this paper seeks to address, namely how similarly the English and Scottish formulae allocate resources, and how these allocations may or may not differ from actual allocations under Barnett.

\section{Conclusions}

The Barnett Formula, used to allocate resources to the UK's devolved territories, has long been criticised on the grounds that it makes no attempt to estimate the spending needs of those territories. There are increasing calls to replace the Barnett Formula with an alternative mechanism that allocates grant on the basis of some estimate of the territories' spending needs. At the same time however, many commentators argue that developing a spending needs model for the UK territories would be fundamentally intractable, given that needs formulae require normative judgements about what constitutes need, and can be subject to political manipulation.

This paper compares two existing formulae for estimating healthcare spending needs. The rationale is to test whether the two formulae - developed by different researchers using different data, and working within different political frameworks - provide similar or very different estimates of the healthcare spending needs of the UK territories.

The two formulae considered are the allocation formulae used by the NHS in England and the NHS in Scotland to allocate resources to PCTs and Health Boards respectively. Although it would never be possible to say that one of these formulae was more accurate, or 'right' than the other, both formulae are 'trusted' in the sense that they have been used by politicians of different persuasion to guide territorial resource allocation for several decades.

Results show that the two formulae do provide very similar estimates of the spending need of UK regions and territories, despite relying on a wide variety of different needs indicators. For most regions, the difference between the two formulae in the allocation of healthcare resources amounts to less than 3\% per capita. The English formula tends to allocate slightly more resources to urban 
areas facing higher factor costs and higher levels of labour-market disadvantage. The Scottish formula tends to allocate relatively more resources to rural areas. This result is neither alarming nor surprising. Rather than being due to normative differences between the formulae in what constitutes a need, it stems from the fact that the two formulae have been developed based on evidence from territories with slightly differing characteristics (i.e. there are no remote island PCTs in England which explains why the English formula is less sensitive to the needs of Scottish island PCTs).

Both the Scottish and English formulae agree that Wales, Scotland and NI have higher healthcare spending needs than England. In comparison to actual relative spending on healthcare, the results of both formulae also appear to re-enforce the view that levels of public spending are relatively generous (compared to need) in Scotland and NI, but less so in Wales (MORGAN, 2001; MCLEAN and MCMILLAN, 2003). Of course, the block grant allocations to the DAs are not earmarked, so Wales could increase spending on healthcare if it chose. But this would inevitably lead to a reduction in spending on other devolved policy areas, which, given the proportion of the Welsh Government's spending that it is on health, could be significant ${ }^{\mathrm{ii}}$. It is also the case that variations in spending per capita might not translate into variations in the quality of health services provided, as differences in health policy may lead to differences in the efficiency of the NHS in the different territories (CONNOLLY et al., 2010; NATIONAL AUDIT OFFICE [NAO], 2012). Nonetheless, in the absence of appropriate data from which reliable estimates of the efficiency of healthcare spending across the UK territories can be assessed, spending per capita will remain the benchmark from which judgements about the fairness of territorial resource allocation will be made.

The fact that the two NHS allocation formulae provide similar estimates of spending need is promising for those who would prefer to see the Barnett Formula replaced by needs assessment. There remain however a number of issues to resolve in seeking to develop a UK-wide needs estimate formula as a replacement for Barnett. First is that the Barnett Formula is used to determine the block grant to the DAs for all policy areas. It remains to be seen whether the similarity between the Scottish and English health formula would be replicated to such an extent for other public services, but some evidence (for local government services, including education) suggest that there are similarities in how the Scottish and English formulae estimate the territories spending needs for these services (KING et al. 2007; BALL et al. 2012).

Second, the healthcare allocation formulae used to allocate resources to PCTs within England and Scotland are fairly complex. At a UK level, a future needs assessment model will probably need to be significantly more transparent. Indeed, both the Holtham Commission and the House of Lords 
Committee reports have argued that any Barnett Formula replacement needs to be based around a simple, single-equation formula. In developing a Barnett-replacement however the NHS formulae are likely to be useful in informing the types of indicators that might be used. The analysis in this paper for example has demonstrated how estimates of a territory's need for health spending vary depending on the relative weights attached to mortality as opposed to socio-economic deprivation proxies of healthcare spending need.

Third, needs assessments are inherently political, and this poses potential difficulties when attempting to develop a needs assessment model that can be applied across territories with distinct policy-making responsibilities. The example of the health inequalities component of the English health allocation formula, the weighting of which is changed by Ministers with significant allocative consequences, is one example of this. There is evidence that devolution of responsibility for healthcare (which occurred in 1999), is manifesting itself in divergence in policy and performance management across the four countries (GREER 2004, FORBES et al., 2010). This divergence is most pronounced in the use of competition between healthcare providers, and in the use of payment-byresult type contracts to fund hospital activities (NAO, 2012).

This policy divergence is likely to increase the difficulties associated with agreeing what constitutes a legitimate spending need. In Spain, which operates an system of asymmetric devolution which has similarities with the UK position, attempts to establish a formula to compensate the Autonomous Communities' spending needs were so contested that the resulting formula is extremely simple, relying on a small basket of demographic and area indicators to estimate the spending needs associated with health, education and social services (BÖSCH, 2009). On the other hand, Australia operates a detailed system of needs assessment to allocate resources to the Australian states (which do have a reasonable degree of policy-making and tax-raising autonomy) (SELECT COMMITTEE ON THE BARNETT FORMULA 2009). The Australian needs assessment system is overseen by an independent commission in a manner not dissimilar to the way that independent commissions inform the development of the NHS allocation formulae discussed in this paper.

The Barnett Formula has proved remarkably resilient over the past 30 years as the tool for allocating resources to the UK territories. Despite regular criticism, its durability seems to result from the observation that it codifies a bargaining outcome (SMITH, 2003). However, on-going political and fiscal devolution in the UK will result in more pressure to replace Barnett. And as the DAs gain more fiscal autonomy, there is an argument to say that demand for a 'fairer' system of allocating resources to the territories will grow, driven in particular by the emergence of a new 'English political community' (LODGE et al. 2012). Inevitably, developing needs-based models on which all 
DAs agree will prove challenging. But the fact that England's and Scotland's healthcare allocation formulae generate such similar estimates of the DAs healthcare spending needs suggests that the scope for agreement on this, the largest area of DA expenditure, may be greater than some have supposed.

\section{References}

Ball, R., King, D., \& Eiser, D. (2011, December). Assessing the relative healthcare spending needs of the UK's devolved territories: an English perspective. Retrieved from http://www.barnett-orneeds.stir.ac.uk/Publications.html

Ball, R., King, D., \& Eiser, D. (2012). Assesing the relative healthcare needs of the UK's devolved territories: a Scottish perspective. Environment and Planning C: Government and Policy, 30(2), 322-346.

Ball, R., King, D., \& Eiser, D. (2012b). Estimating education spending needs for the UK's devolved territories. Working Paper, University of Stirling.

Blöchliger, H., \& King, D. (2006). Less than you thought: the fiscal autonomy of sub-central governments. OECD Economic Studies, 43(2), pp. 155-188.

Bosch, N. (2009). The reform of regional government finances in Spain. In World Report on Fiscal Federalism. Barcelona: Institut d'Economia de Barcelona.

Carr-Hill, R., Martin, S., Peacock, S., Sheldon, T., \& Smith, P. (1997). A new formula for distributing hospital funds in England. Interfaces, 27(1), 53-70.

Christie, A., \& Swales, K. (2010). The Barnett allocation mechanism: formula plus influence? Regional Studies, 44(6), 761-755.

Commonwealth Grants Commission. (2010). Report on GST Revenue Sharing Relativities - 2010 Review. Canberra: Commonwealth of Australia.

Connolly, S., Bevan, G., \& Mays, N. (2010). Funding and performance of healthcare systems in the four countries of the UK before and after devolution. London: Nuffield Trust.

Department of Health. (2009a). Resource allocation: weighted capitation formula, sixth addition. London.

Department of Health. (2009b). 2009-10 and 2010-11 PCT Revenue Allocations. Retrieved August 2, 2011, from http://www.dh.gov.uk/prod_consum_dh/groups/dh_digitalassets/@dh/@en/documents/di gitalasset/dh_091447.pdf 
Department of Health. (2010). Equity and Excellence: Liberating the NHS. London: Department of Health.

Forbes, T., Evans, D., \& Scott, N. (2010). Implementing health and social care policy: England and Scotland compared. Policy Studies, 31(6), 591-611.

Galbraith, J., \& Stone, M. (2011). The abuse of regression in the National Health Service allocation formulae: response to the Department of Health's 2007 'resource allocation research paper'. Journal of the Royal Statistical Society A, 174(3), 547-567.

Greer, S. (2004). Four way bet: how devolution has led to four different models for the NHS. London: UCL Constitution Unit.

Hallwood, P., \& MacDonald, R. (2009). The political economy of financing Scottish government. Cheltenham: Edward Elgar.

Hanlon, P., Lawder, R., Buchanan, D., Redpath, A., Walsh, D., Wood, R., . . Chalmers, J. (2005). Why is mortality higher in Scotland than in England and Wales? Decreasing influence of socioeconomic deprivation between 1981 and 2001 supports the existence of a 'Scottish effect'. Journal of Public Health, 27(2), 199-204.

Hilber, C., Lyytikäinen, T., \& Vermeulen, W. (2011). Capitalisation of central government grants into local house prices: panel data evidence from England. Regional Science and Urban Economics, 41(4), 394-406.

HM Treasury. (2010b). Budget 2010. London: The Stationary Office.

HM Treasury. (2012). Public Expenditure Statistical Analysis. London: The Stationary Office.

House of Commons Health Committee. (2009). Health Inequalities: Third report of session, 2008-9. London: The Stationary Office.

Independent Commission on Funding and Finance for Wales. (2010). Fairness and Accountability: a new funding settlement for Wales. Cardiff: Welsh Assembly Government.

Jeffery, C. (2012). Dis-united Kingdom? Public Policy Research, 19(1), 14-16.

John, P., \& Ward, H. (2001). Political manipulation in a majoritarian democracy: central government targeting of public funds to English subnational government, in space and across time. British Journal of Politics and International Relations, 3(3), 308-339.

Kay, A., Bristow, G., McGovern, M., \& Pickernell, D. (2005). Fair division or fair dinkum? Australian lessons for intergovernmental fiscal relations in the United Kingdom. Environment and Planning C, 23, 247-261.

King, D., Pashley, M., \& Ball, R. (2007). Scotland's social services spending needs: an English view. Environment and Planning C: Government and Policy, 25, 918-940.

Lago-Penas, I., Lago-Penas, S., \& Martinez-Vazquez, J. (2011). Guest Editorial, The political and economic consequences of decentralisation. Environment and Planning C, 29(2), 197-203. 
Lodge, G., Wincott, D., Henderson, A., \& Jones, R. W. (2012). The dog that finally barked: England as an emerging political community. London: Institute for Public Policy Research.

Mackay, R., \& Williams, J. (2005). Thinking about need: public funding on the regions. Regional Studies, 39(6), 815-828.

McLaren, J., Armstrong, J., \& Harris, R. (2010). Spending on health. Glasgow: Centre for Public Policy for Regions.

McLean, I., \& McMillan, A. (2003). The distribution of public expenditure across the UK regions. Fiscal Studies, 24(1), 45-71.

McLean, I., Lodge, G., \& Schmueker, K. (2008). Fair Shares? Barnett and the politics of public expenditure. Institute for Public Policy Research.

Midwinter, A. (2002). Territorial resource allocation in the UK: a rejoinder on needs assessment. Regional studies, 36(5), 563-567.

Morgan, K. (2001). The new territorial politics: rivalry and justice in post-devolution Britain. Regional Studies, 34, 343-48.

National Audit Office. (2011). Formula funding of local public services. London: The Stationary Office.

National Audit Office. (2012). Healthcare across the UK: a comparison of the NHS in England, Scotland, Wales and Northern Ireland. London: The Stationary Office.

NHS Scotland Resource Allocation Committee. (2007). Delivering Fair Shares for Health in Scotland. Edinburgh: NHS Scotland.

Nuffield Trust. (2009). Developing a person-based resource allocation formula for allocations to general practices in England. London: Nuffield Trust.

Select Committee on the Barnett Formula. (2009). The Barnett Formula. London: Authority of the House of Lords.

Smith, P. (2007). Formula Funding of Public Services. Abingdon: Routledge.

Smith, P. C. (2003). Formula funding of public services: an economic analysis. Oxford Review of Economic Policy, 19(2), 301-322.

Stone, M., \& Galbraith, J. (2006). How not to fund hospital and community health services in England. Journal of the Royal Statistical Society A, 169(1), 143-164. 


\section{Tables}

Table 1: Spending on healthcare in UK territories

\begin{tabular}{lrrrr}
\hline & England & Wales & Scotland & $\mathrm{NI}$ \\
\hline Healthcare spending per capita & $£ 1,643$ & $£ 1,769$ & $£ 1,871$ & $f 1,783$ \\
\hline Index of per capita health spending (England=1) & 1.000 & 1.077 & 1.139 & 1.085 \\
\hline Spending on health as \% all devolved spending & - & $34.3 \%$ & $33.0 \%$ & $34.2 \%$ \\
\hline
\end{tabular}

Source: Public Expenditure Statistical Analyses (HM Treasury 2012)

Note: Figures on spend per capita are averages over 2005/6 - 2010/11 in 2012 prices. Devolved spending for Wales and Scotland is defined as spending on health, education, local government, transport, environment, housing, culture and tourism, and policing, but excluding defence, foreign affairs and welfare. Devolved spending for $\mathrm{NI}$ is defined the same way with the exception of policing, which is considered non-devolved. 


\begin{tabular}{|c|c|c|}
\hline & English formula & Scottish formula \\
\hline \multirow[t]{6}{*}{ HCHS } & Age indicators & \\
\hline & - $\quad$ GP-registered population in 18 age groups, 2009 & - $\quad$ GP-registered population in 20 age groups, by male and female, 2009 \\
\hline & Additional need indicators & \\
\hline & 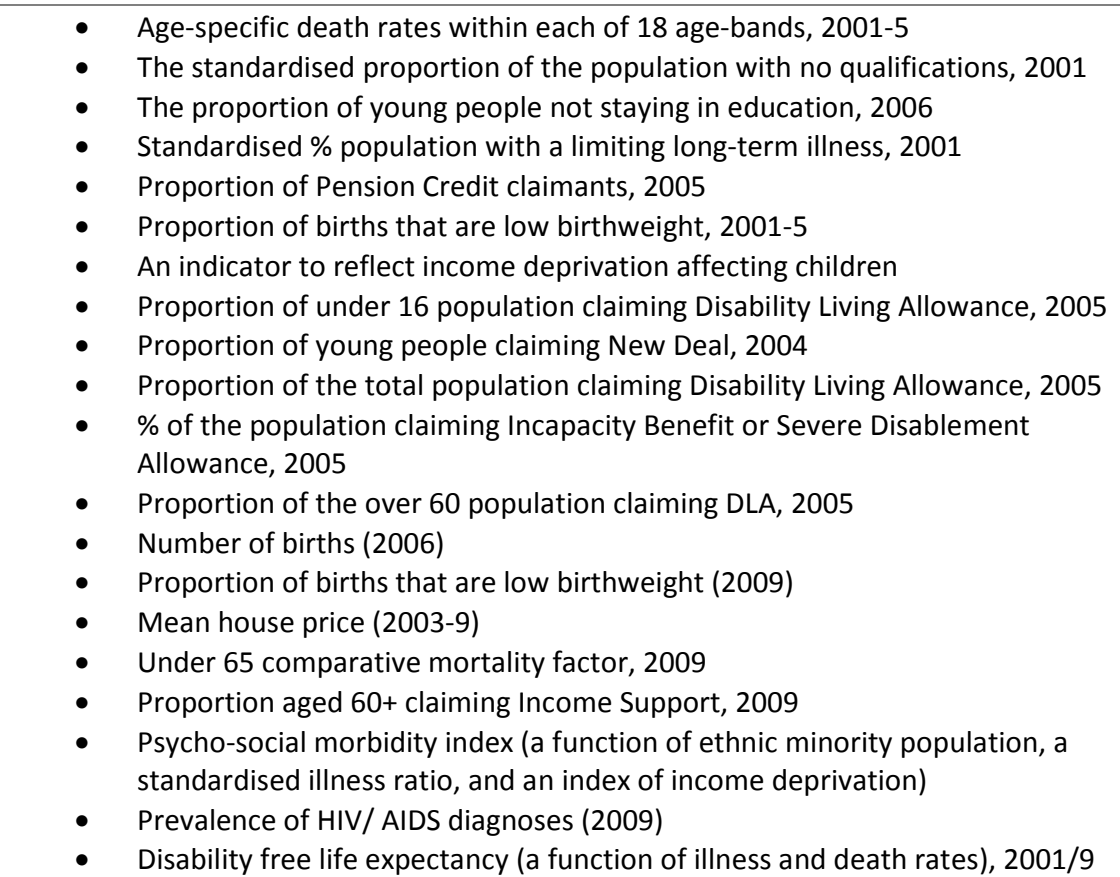 & $\begin{array}{l}\text { - } \quad \text { All cause standardized mortality rate, age } 75 \text { and under (2001-5) } \\
\text { - } \quad \text { Limiting long-term illness rate, age-sex standardized (2001) } \\
\text { - } \quad \text { of } 16+\text { population claiming Severe Disablement Allowance (2004) } \\
\text { - } \quad \text { Proportion of households that are one person (2001) } \\
\text { - } \quad \text { Mean house price (2003-9) } \\
\text { - } \quad \text { Birth rate per female population aged } 15-44(2009) \\
\text { - Urban rural supplementary variable (2004) }\end{array}$ \\
\hline & Cost indicators & \\
\hline & $\begin{array}{l}\text { - } \quad \text { Standardised spatial wage differentials, 2007-9 } \\
\text { - } \quad \text { Land and buildings cost index, } 2004 \\
\end{array}$ & $\begin{array}{l}\text { - Proportion of population living in each of ten geographical categories } \\
\text { (from Primary city to very remote island), } 2001\end{array}$ \\
\hline \multirow[t]{4}{*}{ Prescribing } & Age indicators & \\
\hline & - $\quad$ GP-registered population in 9 age groups, males and females, 2009 & - $\quad$ GP-registered population in 9 age groups, males and females, 2009 \\
\hline & Additional need indicators & \\
\hline & $\begin{array}{l}\text { - } \quad \text { Percentage population with long-term limiting illness } \\
\text { - } \quad \text { Proportion Disability Living Allowance Claimants } \\
\text { - } \quad \text { Low Income Scheme index } \\
\text { - Proportion births that are low birthweight }\end{array}$ & $\begin{array}{l}\text { - } \quad \text { All cause standardized mortality rate, age } 75 \text { and under (2001-5) } \\
\text { - } \quad \text { Limiting long-term illness rate, age-sex standardized (2001) }\end{array}$ \\
\hline
\end{tabular}


- Disability free life expectancy, 2001/9

\begin{tabular}{|c|c|c|}
\hline PMS & Age indicators & $\mathrm{n} / \mathrm{a}$ \\
\hline & - $\quad$ Population in 7 age groups, male and female, 2009 & \\
\hline & Additional need indicators & \\
\hline & $\begin{array}{l}\text { - Age-sex standardised proportion of population with long-term limiting illness } \\
\text { (2001) } \\
\text { - Under } 65 \text { standardised mortality ratio, } 2009 \\
\text { - } \quad \text { Disability free life expectancy, } 2001 / 9\end{array}$ & \\
\hline & Cost indicators & \\
\hline & $\begin{array}{l}\text { - } \quad \text { Standardised spatial wage differentials, 2007-9 } \\
\text { - } \quad \text { Land and buildings cost index, } 2004 \\
\text { - } \quad \text { Index of multiple deprivation, } 2010\end{array}$ & \\
\hline
\end{tabular}


Table 3: Estimates of the healthcare spending needs of the UK devolved territories: comparing the results of the English and Scottish NHS allocation formulae

\begin{tabular}{lcccccccc}
\hline & \multicolumn{3}{c}{ English NHS formula } & \multicolumn{4}{c}{ Scottish NHS formula } \\
& England & Wales & Scotland & NI & England & Wales & Scotland & NI \\
\hline Age & 1.000 & 1.044 & 1.009 & 0.932 & 1.000 & 1.035 & 0.997 & 0.937 \\
Additional need & 1.000 & 1.086 & 1.086 & 1.134 & 1.000 & 1.055 & 1.110 & 1.104 \\
Cost & 1.000 & 0.968 & 0.977 & 0.969 & 1.000 & 1.002 & 1.007 & 1.006 \\
\hline Total need & $\mathbf{1 . 0 0 0}$ & $\mathbf{1 . 0 9 7}$ & $\mathbf{1 . 0 7 2}$ & $\mathbf{1 . 0 2 4}$ & $\mathbf{1 . 0 0 0}$ & $\mathbf{1 . 0 9 5}$ & $\mathbf{1 . 1 1 4}$ & $\mathbf{1 . 0 3 9}$ \\
\hline
\end{tabular}

Table 4: Estimates of the healthcare spending needs of the UK devolved territories, including an adjustment for Health Inequalities

\begin{tabular}{lccccccccc} 
& \multicolumn{3}{c}{ English NHS formula } & \multicolumn{4}{c}{ Scottish NHS formula } \\
& England & Wales & Scotland & NI & England & Wales & Scotland & NI \\
\hline $\begin{array}{l}\text { Health } \\
\text { inequalities score }\end{array}$ & 1.000 & 1.607 & 1.443 & 1.585 & 1.000 & 1.607 & 1.443 & 1.585 \\
\hline Total need & $\mathbf{1 . 0 0 0}$ & $\mathbf{1 . 1 5 5}$ & $\mathbf{1 . 1 1 7}$ & $\mathbf{1 . 0 9 1}$ & $\mathbf{1 . 0 0 0}$ & $\mathbf{1 . 1 6 1}$ & $\mathbf{1 . 1 5 6}$ & $\mathbf{1 . 1 1}$ \\
\hline
\end{tabular}




\section{Figures}

Figure 1: Comparing the English and Scottish allocation formulae's assessment of the spending needs of UK territories and regions

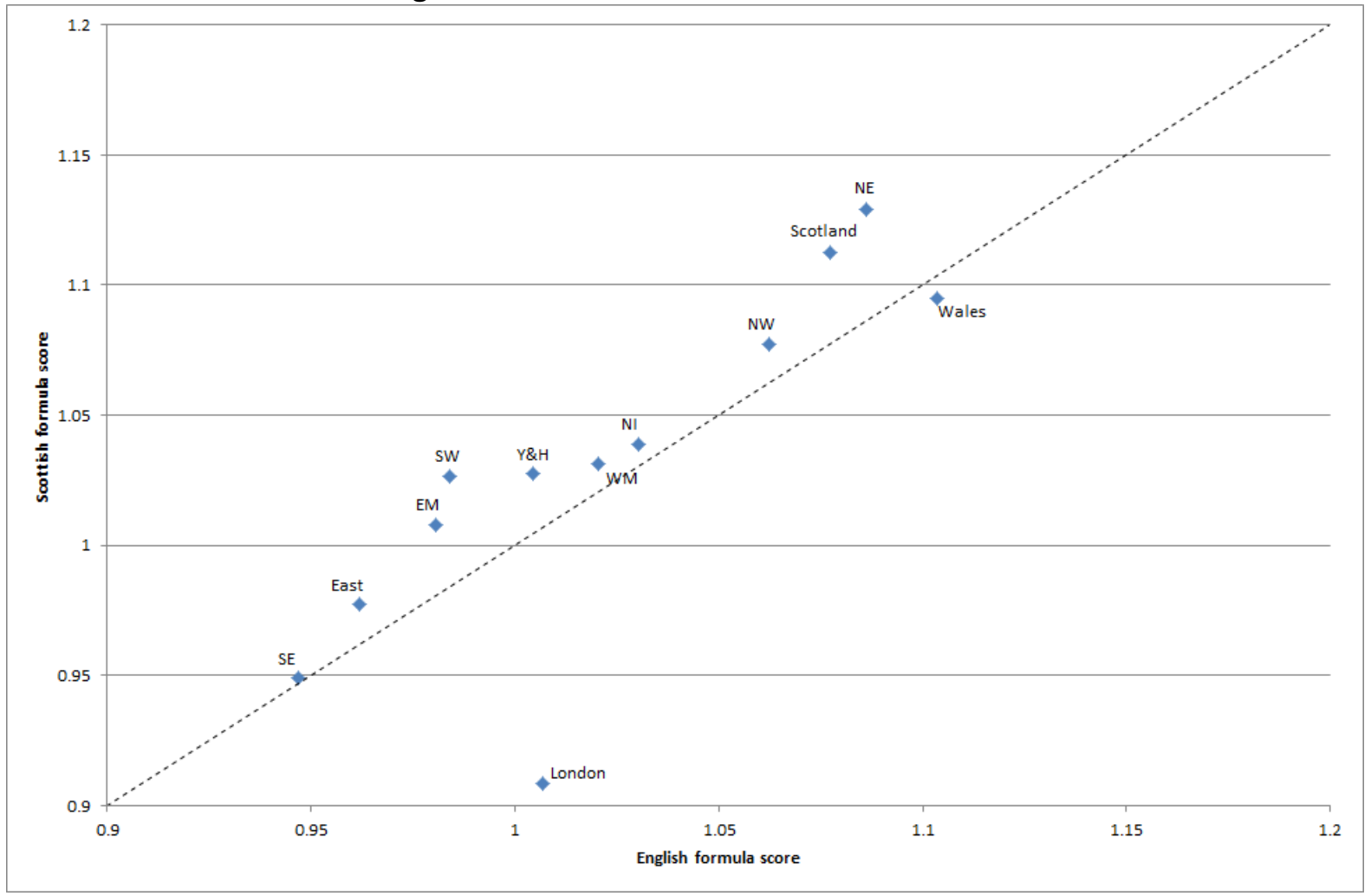

Figure 2: Comparing the English and Scottish allocation formulae's assessment of the spending needs of UK territories and regions, excluding ACA from the English formula

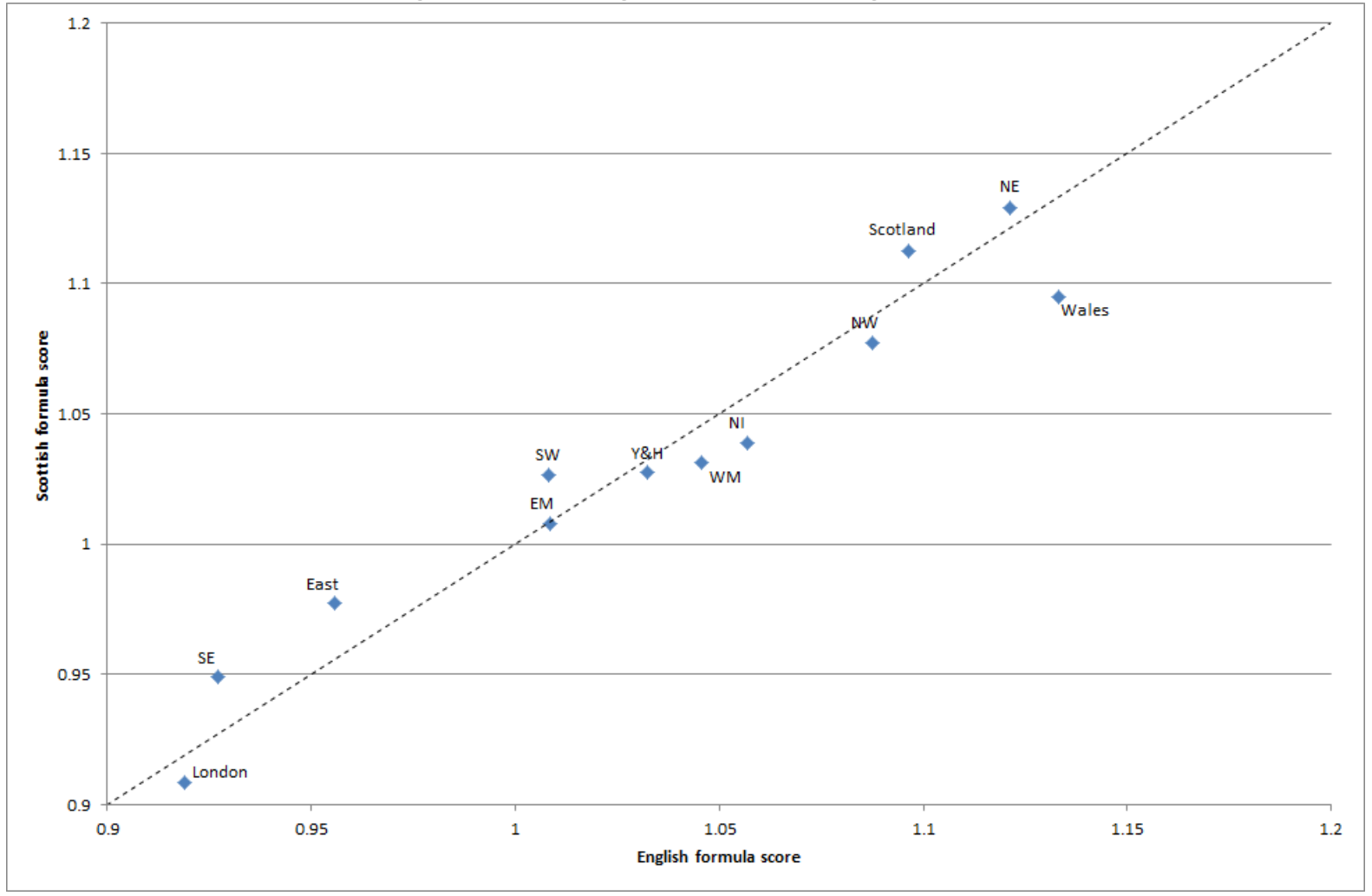




\title{
Endnotes
}

\begin{abstract}
' Data was collated for 148 PCTs in England, 14 Health Boards in Scotland; seven Health Boards in Wales and five Health and Social Care Trusts in Northern Ireland. There are in fact 151 PCTs in England, but due to boundary issues the three Birmingham PCTs were amalgamated into one and the two Cheshire PCTs were also amalgamated into one, for the purpose of this analysis.

ii Indeed, for the Welsh Assembly Government to increase spending on health from the current level to the level that the two formulae suggest it should be spending in order to provide equal access for those with equal need relative to England, this would an imply and increase in health spending of some $£ 30$ per capita, or $£ 90$ million in total. To put this in perspective, f90million represents around $5 \%$ of the Welsh Government's annual spending on children, education and skills.
\end{abstract}

